\title{
ATUAÇÃO PSICOLÓGICA COLETIVA: UMA TRAJETÓRIA PROFISSIONAL EM UNIDADE BÁSICA DE SAÚDE ${ }^{1}$
}

\author{
Mônica Lima*
}

\begin{abstract}
RESUMO. Neste artigo, problematiza-se a realização de práticas psicológicas mais compatíveis com os princípios que orientam a organização da atenção à saúde no SUS e os desafios decorrentes da inserção de psicólogos na saúde coletiva. Tem-se como objetivo apresentar uma proposta de atuação psicológica coletiva como uma estratégia de trabalho no campo da saúde coletiva, destacando a importância de um caráter mais socioculturalmente orientado. Através de entrevistas semiestruturadas descreveram-se trajetórias profissionais de psicólogos, distribuídos em UBSs da Secretária Municipal de Saúde de Salvador-BA, em 2003. Para isto utilizaram-se três modalidades de trajetórias profissionais, considerando as práticas psicológicas desenvolvidas e os significados a elas atribuídos: de conflito, de reprodução e de construção. Definiu-se a atuação psicológica coletiva e tomou-se para este artigo uma trajetória profissional de construção como ponto de partida.
\end{abstract}

Palavras-chave: atuação psicológica coletiva, unidades básicas de saúde, trajetória profissional.

\section{COLLECTIVE PSYCHOLOGICAL PERFORMANCE: A PROFESSIONAL TRAJECTORY IN A BASIC HEALTH UNIT}

\begin{abstract}
In this article psychological practices compatible with the principles of organization in healthcare units (SUS) and the challenges due to the insertion of psychologists in public health services are discussed. This study aims to present a proposal of a collective psychological work as a strategy in the field of Public Health. The study focuses on the importance of a more sociocultural oriented character. Through the use of semi-structured interviews, the study describes the professional trajectories of psychologists in health services associated to the municipal Health Department in Salvador, Bahia, 2003. Three types of professional trajectories were described taking into consideration the psychological practices developed, and the meaning attributed to them: conflict, reproduction, and construction. The collective psychological performance was defined taking the professional trajectory of construction as a starting point.
\end{abstract}

Key words: collective psychological performance, basic health units, professional trajectories.

A difusão de psicólogos no campo da saúde pública, antes circunscrita a serviços especializados de saúde mental, é considerada emergente no Brasil. Essa expansão é atribuída às ações sociais e políticas para a efetivação da reforma psiquiátrica, as quais impulsionaram a crítica ao modelo asilar, e às intervenções multiprofissionais para a melhoria da qualidade da assistência à saúde mental, reforçadas pela busca do Estado por diminuir os custos hospitalares e ampliar as atenções secundária e primária (Bastos \& Achcar, 1994; Dimenstein, 1998; Lo Bianco, Bastos, Nunes \& Silva, 1994).

Segundo Dimenstein (1998), os seguintes fatores foram decisivos para aumentar a entrada do psicólogo nos serviços públicos de saúde: a) o contexto das políticas públicas de saúde do final dos anos de 1970 e em toda a década de 1980, particularmente a repercussão no setor de recursos humanos; b) a diminuição de busca aos consultórios de psicologia por parte da população, causada por seu empobrecimento, a partir dos anos de 1980; c) o movimento da própria categoria com o objetivo de redefinir a função social da psicologia na sociedade; d) a difusão da psicanálise e a psicologização da sociedade. Em relação a esses últimos fenômenos, Russo (2002, p. 43) ressalta que a difusão da psicanálise opera como a força motriz para o processo de psicologização da sociedade, ou seja, "a volta para dentro de si mesmo [...] uma busca "dentro de si" para o que antes estava 'fora' - parâmetros, regras,

\footnotetext{
Apoio: CNPq.

* Doutora. Docente do departamento de Psicologia da Universidade Federal do Vale do São Francisco-UNIVASF.
} 
orientação", que dá sentido a aspectos significativos da vida.

Um dos pontos fundamentais que explicaria o descompasso entre as demandas e as necessidades de atendimento psicológico dentro dos serviços públicos de saúde é a transposição de alguns dos elementos que fundamentam a "clínica tradicional" para todos os níveis de assistência à saúde, independentemente das suas particularidades (Lo Bianco e cols. 1994). A clínica tradicional é caracterizada pelos seguintes aspectos: a) a ênfase na oferta de psicodiagnóstico e/ou terapia individual ou grupal; b) maior familiaridade do profissional com a clientela proveniente de segmentos sociais mais abastados; c) a ênfase na dimensão intra-individual dos pacientes, evidenciando os processos psicológicos e psicopatológicos; e) a percepção do indivíduo como abstrato e anistórico. Observamos que a tentativa de caracterizar a clínica tradicional presente nesse modelo hegemônico busca considerar desde o espaço em que ela é desenvolvida, suas técnicas e estratégias utilizadas, a ênfase atribuída a determinado foco para a compreensão do fenômeno psicológico até a natureza da relação entre o psicólogo e o paciente.

Um dos pontos nodais que sustenta as reflexões sobre como tem ocorrido a inserção e a atuação do psicólogo nos serviços públicos de saúde diz respeito ao seu despreparo para esse tipo de trabalho, decorrente da formação profissional oferecida e reforçada nos cursos de Psicologia (Boarini, 1993; 1996; Bastos \& Achcar, 1994; Dimenstein, 1998; 2000; Silva, 1992). Segundo Silva (1992), destaca-se o fato de as propostas clínicas apresentadas durante a graduação em Psicologia continuarem orientadas e direcionadas por parâmetros típicos da classe média, utilizados para a padronização de seus instrumentos, métodos e técnicas, linguagem e valores em geral.

Ressalta-se o fato de, em outros estados brasileiros, a inserção dos psicólogos na área de saúde pública ser analisada também como problemática. Spink (2003), descrevendo este movimento dos psicólogos para as UBSs de São Paulo, em 1985, já questionava o que eles deveriam fazer neste nível de assistência. Há nas falas de seus entrevistados, e também nas de Dimenstein (1998), a mesma percepção de não familiaridade e de premente "desespero" nos primeiros contatos com este espaço de trabalho, tal como encontramos entre os nossos interlocutores (Lima, 2005).

Lo Bianco e cols. (1994) ressaltam que a inserção do psicólogo na rede básica de saúde deveria atentar para os seguintes aspectos: a) ênfase no planejamento e execução de ações com base em demandas coletivas; b) atenção às especificidades trazidas pela "pulverização" de problemas específicos de saúde trazidos pela população; c) a necessidade de lidar com contingentes maiores de indivíduos, levando a priorizar estratégias grupais e focais para lidar com os problemas trazidos pela população; d) o fato de ter contato direto com as condições concretas de vida do segmento populacional não privilegiado economicamente da sociedade, poder checar seus conceitos universalizantes de psiquismo: e) a percepção de que a concepção de 'clínica psicológica' pode abarcar ações de baixa complexidade, não a restringindo às ações psicoterápicas especializadas, mas buscando incluir práticas preventivas e voltadas à promoção da saúde.

Apesar do esforço dos referidos autores para elencar as ações e noções que seria mais pertinente serem reforçadas na formação e desenvolvidas pelos psicólogos nas UBSs, alguns dos aspectos levantados estão por ser desdobrados ou mesmo definidos. Está obscuro o que significa "demanda coletiva" e o que se quer dizer com "pulverização" dos problemas específicos. Além disso, o emprego de trabalho em grupo justificado pelo aumento da demanda parecenos um ponto de partida da reflexão, e não uma deliberação que se deva aceitar sem ressalvas.

Em Salvador, a inserção dos psicólogos nas UBSs ocorreu na década de 1990, um pouco mais tardiamente do que em outros estados do Brasil (Lima, 2005). No entanto, após mais de três décadas da entrada do primeiro profissional de psicologia na rede pública de saúde, a despeito do relevo que esta problemática vem tendo no panorama nacional, há uma lacuna de estudos sobre a inserção e a atuação dos psicólogos na Bahia no campo da saúde pública.

Neste sentido, no presente artigo, interpretamos as experiências concretas de psicólogos que atuam no setor de saúde pública de Salvador, buscando contribuir para a definição de uma estratégia de atuação psicológica para UBSs. Para tanto, tomamos uma trajetória profissional de construção como ponto de partida e alicerçamos sua compreensão nas discussões e noções significativas que envolvem e integram os campos da psicologia e da saúde coletiva.

Nessa perspectiva, a definição de atuação psicológica coletiva (APC) proposta deve estar orientada pelo compromisso social (Bock, 1999; 2003) no sentido de incorporar e avançar em proposições que alimentem práticas socialmente contextualizadas para o psicólogo como profissional de saúde. A APC deve estar fundamentada nos princípios do Sistema Único de Saúde - SUS (Paim, 1999), como eixos orientadores das práticas psicológicas oferecidas para 
uma finalidade que não se esgota no indivíduo nem é de exclusividade do setor da Saúde. A APC deve considerar os aspectos fundamentais para o trabalho do psicólogo no SUS, de modo a contribuir para o oferecimento de ações mais pertinentes à atenção primária à saúde (Dimenstein, 1998). Por fim, ela deve buscar se distanciar dos efeitos negativos do emprego da clínica tradicional (Lo Bianco \& cols., 1994).

\section{MODELO TEÓRICO-METODOLÓGICO}

O trabalho de campo, neste estudo, ocorreu entre os anos de 2002 a 2003, quando entrevistamos 21 psicólogos dos 24 empregados na assistência direta à população, em cinco unidades básicas (UBSs) e três centros de saúde mental (CSMs), vinculados à Secretária de Saúde Municipal (SMS) de Salvador. Neste artigo, analisamos particularmente as sete trajetórias profissionais desenvolvidas nas UBSs de Salvador, parte dos dados empíricos da tese intitulada "Atuação Psicológica em Serviços Públicos de Saúde de Salvador: do ponto de vista dos psicólogos" (Lima, 2005). Tal estudo foi submetido e aprovado pelo Conselho de Ética de Pesquisa do ISC/UFBA (Doc. $N^{\circ}$ 023-03/CEP-ISC). Houve a solicitação dos consentimentos livres e esclarecidos da SMS de Salvador e de todos os entrevistados (Resolução 196/96 do Conselho Nacional de Saúde).

No processo de coleta e análise dos dados, descrevemos as trajetórias profissionais dos entrevistados, ressaltando as experiências concretas e os modelos explicativos (Almeida-Filho, Coelho \& Peres, 1999; Bibeau, 1992) construídos sobre as práticas psicológicas oferecidas, as dificuldades e desafios para a realização das mesmas e sobre os problemas de saúde apresentados pelos usuários encaminhados para o atendimento psicológico.

Além disso, consideramos que tais experiências profissionais podem ser compreendidas a partir da metáfora do texto: a ação é constituída de significados e pode ser lida como um texto (Geertz, 1989). Há uma específica relação entre a produção dialógica proveniente do trabalho de campo e a sua interpretação a posteriori, sustentada pelos conceitos de texto e de inscrição: "texto é todo discurso fixado pela escrita" e "inscrição é a fixação do significado em alguma forma de registro" (Ricoeur, 1991). Na escrita etnográfica interpretativa, inscrever a ação possibilita a passagem da mera descrição dos fatos e modelos explicativos nativos para a elaboração de uma interpretação do pesquisador (Geertz, 1989).

\section{TRAJETÓRIAS PROFISSIONAIS: DE CONFLITO, DE REPRODUÇÃO E DE CONSTRUÇÃO}

Descrevemos três modalidades de trajetória profissional dos psicólogos nos serviços públicos de saúde: a) de conflito, que tende à ociosidade do profissional; b) de reprodução, que conduz ao isolamento típico da assistência ambulatorial; e c) de construção, que demonstra certa abertura para a busca de atuação fora da clínica tradicional.

Nas trajetórias de conflito e de reprodução, podemos identificar uma tendência à compreensão restrita do fenômeno psicológico, em que o foco das descrições narrativas dos problemas de saúde dos usuários está, predominantemente, centrado em aspectos intra-individuais. Na trajetória de construção há uma abertura no sentido do uso de outras técnicas de intervenção mais educativas e o trabalho em grupo. Percebemos uma compreensão menos restrita do fenômeno psicológico: proveniente de narrativas que incluem as condições de vida e aspectos sociais das demandas trazidas pelos usuários como aspectos que influenciam os seus problemas de saúde.

As modalidades de trajetória profissional diferenciam-se pela natureza da intervenção e se unem pela forte influência da Psicanálise como visão de mundo, que orienta as práticas psicológicas desenvolvidas pela maioria dos profissionais. Esta categorização tem como ponto de partida uma dicotomia marcada: a) pela diferença de enquadre da atuação em individual ou grupal; b) pela influência da orientação teórica e dos recursos utilizados, pelo atravessamento do grau de "pureza" da psicanálise aplicada.

Em certo sentido, consideramos que o profissional cujo trabalho é organizado no enquadre grupal e na ampliação dos recursos técnicos para a intervenção, que ensaia trabalhos mais integrados e de cunho mais preventivo e de promoção da saúde dentro de UBSs, tende a ser aquele que apresenta uma certa abertura para construir um modelo de atuação psicológica apontado como mais adequado ao nível de assistência primário, sendo um tipo convergente do que definimos como atuação psicológica coletiva.

Ainda que toda categorização reforce uma idéia subjacente de homogeneidade, há particularidades em cada uma das trajetórias profissionais, cujo detalhamento nos distanciaria dos objetivos desse artigo. Cabe ressaltar que as variações encontradas nas modalidades de trajetória profissional reconstruídas estão condicionadas ao grau de flexibilidade da gerência, à possibilidade de organizar o trabalho nos 
moldes da clínica tradicional de consultório particular e à capacidade de lidar com os desafios decorrentes do seu encontro com a população mais pobre.

Não há muita diferença entre os tipos de prática psicológica oferecidos em UBSs e centros de saúde mental, pois predominam as psicoterapias individuais de base psicanalítica. Em relação à orientação teórica dos entrevistados, percebemos a forte influência da psicanálise também presente para a definição da sua identidade profissional, sugerindo uma fusão identitária entre o psicólogo e o psicanalista (Lima, 2005).

A fusão identitária psicólogo-psicanalista, quando desenvolvida dentro do contexto dos serviços de saúde públicos, é marcada pelo fato de os profissionais poderem ser mais ou menos psicanalistas do que o são nos consultórios particulares. Esta assertiva decorre do fato de que tal atuação psicológica exige uma modelagem particular no que se refere aos ajustes no enquadre clínico e no próprio papel do profissional na direção do tratamento, que pode assumir, curiosamente, uma postura mais incisiva ou diretiva. No entanto, a maioria dos psicólogos das UBSs, independentemente da orientação teórica, aponta a necessidade de adequar de algum modo sua atuação às demandas dos usuários que buscam os serviços públicos de saúde, ressaltando que a "visão de mundo" prevalece sobre a técnica.

Neste particular, em detrimento da orientação teórica, a hipótese discutida foi que o preconceito tecnológico (Goldberg, 2001) causa dificuldade para os profissionais realizarem práticas fora do repertório comportamental fornecido pela formação profissional. Segundo Goldberg (2001), por preconceito tecnológico enfatiza-se uma certa maneira de se realizarem práticas que cada profissional adota a partir de um repertório comportamental modelado por sua profissão, sem se preocupar com o sujeito que está sob os seus cuidados, muitas vezes cristalizado num nãotratar de tudo o que se fizer fora deste repertório.

Destacamos abaixo um dos fragmentos de uma trajetória de conflito. Nessa, a psicóloga se dizia "ociosa" na UBS em decorrência de a clientela que buscava o tratamento psicológico não permanecer na psicoterapia de orientação psicanalítica oferecida. No entanto, apesar da incompatibilidade entre a demanda psicológica e a natureza do trabalho oferecido, chama a atenção o fato de ela defender esse tipo de abordagem psicológica, apesar da constatação da própria paralisia frente a sua inadequação.

"Numa unidade, eu ainda defendo a posição da psicoterapia, vou ficar defendendo ali, vou ser o último dos moicanos (risos) [...] no geral, eu acho que a coisa é bem mais difícil de você coordenar, o ritmo, a forma de funcionamento da unidade com o trabalho da psicologia, né? Então, o atrito seria que eles queriam muito que a gente fizesse um trabalho em grupo, sala de espera, só que eu não quero fazer esse trabalho de sala de espera, de fazer trabalho informativo, eu não tô aqui pra fazer trabalho informativo" [Psicóloga 01; UBS-01].

Tais dificuldades são reveladoras da ausência de diálogo com outras áreas de saúde, na direção de fazer um trabalho mais integrado ou mesmo de organizar uma atuação mais compatível com a realidade dos serviços públicos de saúde, inclusive das demandas da clientela que aí busca ajuda.

\section{ATUAÇÃO PSICOLÓGICA COLETIVA: UMA ESTRATÉGIA DE TRABALHO EM UBS.}

$\mathrm{O}$ ato de identificar e compreender as práticas psicológicas e os significados a elas atribuídos em unidades básicas e centros de saúde mental de Salvador, a partir da descrição das trajetórias profissionais dos psicólogos e de situações concretas de trabalho, deu-nos suporte empírico para conceituarmos o que denominados atuação psicológica coletiva (APC) (Lima, 2005). APC é o processo contextual de identificação de demandas, de planejamento e de execução de necessidades de atendimento psicológico socioeconômica e culturalmente orientado.

As ações decorrentes desse processo podem ser desenvolvidas pelo psicólogo na área de saúde coletiva, individualmente ou em conjunto com outros profissionais, não sendo restritas ao setor da Saúde. Este deve levar em consideração as críticas e as orientações surgidas dentro e fora do próprio campo disciplinar da psicologia, marcado pelo seu intercâmbio indispensável com o campo da saúde coletiva.

Neste sentido, a APC pode ser ainda entendida como uma "estratégia" de organização contextualizada da atuação psicológica para prevenir doenças e promover saúde em situações de trabalho em saúde coletiva. Definimos APC a partir da interpretação de uma trajetória profissional de construção que apresenta maior abertura e renovação no oferecimento de práticas psicológicas menos tradicionais da Psicologia e afeitas às particularidades do trabalho em UBSs (Lima, 2005). 


\section{UMA TRAJETÓRIA PROFISSIONAL EM UBS: DE ABERTURA E RENOVAÇÃO.}

O primeiro passo para a definição de atuação psicológica coletiva foi destacar como se deu a inserção de Bárbara, nome fíctício de uma das psicólogas da UBS, destacando elementos que facilitam e/ou dificultam esse processo. A sua chegada na Unidade foi acolhedora por parte da gerente. Como já havia outra psicóloga aí inserida, oferecendo psicoterapia, ela soube, através da gerente, que "não havia demanda para as duas" realizarem o mesmo tipo de atividade. Bárbara relata que se sentiu "aliviada" com esta informação, porque não tinha como proposta de trabalho organizá-lo em torno da psicoterapia, ainda que não tivesse claro, naquele momento, o que iria propor. Do seu ponto de vista, o psicólogo, sendo um profissional incomum nas UBSs, não deve ficar $\grave{a}$ disposição de uma demanda baixíssima.

No primeiro momento, percebemos que o sentido atribuído à demanda vai além da quantidade de usuários, que é descrita pela entrevistada como alta. No segundo momento, inclui o significado da demanda psicológica propriamente dita, baseada no argumento de que as pessoas não aderem à psicoterapia [neste caso, de base psicanalítica], ainda que ela não saiba explicar os motivos associados à não-permanência dos usuários no tratamento psicológico. Ela enfatiza esse argumento ao descrever a referida atuação psicológica como ineficaz e pouco prática, como apresentamos no fragmento abaixo:

\begin{abstract}
“[...] é um profissional raro na unidade de saúde, o psicólogo, e que fica à disposição de uma demanda baixíssima, né?. A demanda era até alta, mas as pessoas não ficam para o tratamento [psicoterapia]... Eu não posso dizer por que, por que eu não faço, não sei... Mas eu sinto que não, não é eficaz, prático. E porque, também, eu tenho condições de fazer (PI), primeiro, promoção e prevenção né? A gente tem que... e se você tem tão poucos [psicólogos] né ?[...] e uma demanda grande [usuários] [...] Porque eu acredito, se você fizesse um grupo, as discussões seriam, né? terapêuticas. Porque é sintoma, também. E, também, você atingiria um maior número de pessoas, criaria um vínculo entre elas, né?"
\end{abstract}

A justificativa para o tipo de atuação que Bárbara irá propor se rascunha já no relato acima, tendo como contraponto a atuação psicológica tradicional (Lo Bianco \& cols., 1994). A sua proposta de trabalho só é possível porque a interlocutora se sente habilitada para desenvolver as ações de prevenção e promoção de saúde que acha compatíveis com o referido nível de assistência, no qual está se inserindo. Nesta direção, considerando a escassez do profissional de psicologia, ela adota uma postura pragmática de otimizar o tempo e o esforço da atuação psicológica para o trabalho grupal de cunho preventivo que contemple problemas prevalentes na área de saúde pública, a exemplo do diabetes e da hipertensão, o que podemos acompanhar no fragmento transcrito abaixo:

\begin{abstract}
“acho que tinha que ele [psicólogo] tinha que otimizar o tempo dele... eu, eu acredito que seria mais adequado... que não, não fosse... porque se a gente começasse a olhar mesmo todas as áreas... não (TI) a gente tem muito que se olhar... problema de diabetes, problemas de hipertensão, a gente só trata o diabético e o hipertenso, não trata a pessoa que está propensa a ser diabética ou hipertensa, né?"
\end{abstract}

No que diz respeito à sua relação com os outros colegas de trabalho, Bárbara comenta que sua postura causou certa estranheza, quando the foi oferecida uma agenda para marcação de consultas e ela explicou que não precisaria desse material, pois não atenderia individualmente, em trabalho psicoterapêutico. Aos poucos ela foi se aproximando e demonstrando aos colegas outras possibilidades de atuação do psicólogo que, na sua opinião, têm sido bem aceitas. O momento de ambientação com as atividades já oferecidas na Unidade parece ter sido um período significativo para a inserção da entrevistada.

É interessante sinalizar que o envolvimento da psicóloga com as práticas associadas comumente a outros setores da UBS será algo permanente na sua trajetória, particularmente o de vacinação, não se tratando de uma "obrigação" imposta pela gerência. A noção de atendimento integral parece funcionar como pano de fundo para a organização do seu trabalho, orientado de modo mais integrado, como visto no fragmento abaixo:

“[...] preciso de algumas informações, que eu não tenho, que gostaria que eles passassem para os adolescentes, essa coisas, os adultos... e o pessoal da, da... vacinação já não... mas, agora eles já estão mais tranqüilos... quando eles [os usuários] ficam no preservativo [aconselhamento individual com entrega de preservativos], aí encaminho para vacinação, também. Aí eles falam "no dia que [Bárbara] está atendendo tem mais vacina" [...]. Eu pego o cartão da pessoa... e eu olho... se precisa vacinar. Se eu vejo assim algum ferimento, eu mando... fazer $\mathrm{o}$ 
curativo né? Porque entendendo que não posso tá atendendo tudo... Se tem uma pessoa [outro profissional] ali, né?. E se ele precisar do outro serviço que o Posto possa oferecer, porque ele já tá aqui dentro. A pessoa que sai não vai voltar no outro dia. Diz que vai voltar e não volta. É mais ou menos esse questionamento que as pessoas [profissionais de saúde] têm de que eu trabalho e não trabalho sozinha."

Outro aspecto que podemos destacar, no relato acima, é o fato de os outros profissionais perceberem a diferença em relação à quantidade de usuários encaminhados para a vacinação ou curativo quando ela está fazendo o aconselhamento individual em DSTs/Aids para uma demanda espontânea que flui no serviço. No entanto, há aqueles que questionam sua postura de buscar uma atuação mais integrada como os outros setores da Unidade:

\begin{abstract}
"O questionamento que eu tinha, que até hoje é assim: [Bárbara] é assim... [Bárbara] procura trabalho pra gente, [Bárbara] trabalha e ainda inventa trabalho pra gente... Esse é o questionamento básico: "por que você não vai fazer sua palestra sozinha e me deixa e deixa a vacinação em paz?". Aí, eu tenho que explicar a esses [não são todos os profissionais] que estamos lidando com adolescente... que a saúde é uma coisa mais é completa. [...] Eles acham que eu tenho que fazer o meu trabalho e não preciso envolver curativo, não preciso envolver isso, no meu trabalho, né?"
\end{abstract}

Os argumentos utilizados pela interlocutora, os quais avalizam o empenho em realizar um trabalho mais conjunto, incluem as particularidades do lidar com o adolescente, que, do seu ponto de vista, é de difícil abordagem e exige uma ação mais completa de saúde. A partir do caráter menos cristalizador da postura profissional assumida por Bárbara, observamos que a sua trajetória profissional parece não sofrer do que Goldberg (2001) qualifica como preconceito tecnológico.

Há de fato uma abertura na sua conduta profissional que pode facilitar a definição de uma atuação psicológica mais adequada às UBSs. A trajetória de Bárbara parece operar uma leitura mais conectada entre Indivíduo, sociedade e serviço, uma leitura já apontada por Boarini (1993) como necessitada de materializar-se em ações mais adequadas às particularidades das situações de trabalho em saúde pública, naquelas que vençam as fragilidades dos conhecimentos aprendidos nos espaços acadêmicos e que coloquem em xeque muitas das tradicionais intervenções psicológicas incansavelmente oferecidas.

Logo, nos chama a atenção o fato de Bárbara ter concluído o curso de Psicologia em 2001, tendo ingressado na universidade em 1996, e poder contar com professores-orientadores que têm acesso a uma literatura mais crítica sobre a formação de psicólogos. Ela destaca a mudança curricular do curso de Psicologia e o oferecimento da disciplina "Psicologia da Saúde", diferentemente das outras entrevistadas (Lima, 2005).

Ela apresenta esse aspecto como se a tivesse instrumentalizado, já que teve oportunidade de contato direto com a realidade dos postos de saúde e informações sobre a reforma sanitária brasileira e psiquiátrica, bem como sobre a organização do SUS, seus princípios e diretrizes, os quais usa como fontes potenciais para a operacionalização do seu trabalho. Podemos considerar que a descrição da entrevistada de como se deu sua graduação parece atentar para alguns dos elementos destacados como necessários para a formação de psicólogos que atuarão na saúde pública.

Boarini (1996, p. 129) ressalta os seguintes aspectos confluentes com os apresentados pela entrevistada:

\footnotetext{
"a necessidade de inserir no currículo do curso de psicologia disciplinas que abordem a saúde pública; a inclusão do estágio em UBS como fonte enriquecedora da formação profissional; a necessidade de se criarem situações que possibilitem o trabalho multiprofissional em que todos os aspectos devam estar sob a responsabilidade de professores com experiência na área"
}

Atualmente Bárbara faz formação em Psicologia Social, trabalhando com a perspectiva de grupos operativos. Destaca que esta abordagem, através do trabalho coletivo, busca incentivar o profissional a "fazer parcerias" com a comunidade, identificar os conflitos e funcionar como um facilitador da "reflexão crítica".

Podemos perceber, pelo relato da entrevistada, a confluência da sua abordagem teórico-prática com o princípio de participação social, cara à organização do SUS. A impressão que ainda acompanha Bárbara sobre a referida UBS é que ela está "desconectada" da comunidade, sendo necessário desenvolver nos potenciais usuários uma postura mais participativa, aspecto com que buscou contribuir em dois sentidos: a) nas atividades terapêuticas propriamente ditas; b) na 
divulgação e fomento para criação do Conselho de Saúde local.

Dentre as principais práticas psicológicas desenvolvidas por Bárbara relativas à problemática das DST, HIV e AIDS, podemos citar: a) palestra em uma escola municipal, acompanhamento do programa de vacinação; b) aconselhamento individual para uma demanda espontânea; c) trabalho de grupo com adolescentes. De acordo com a entrevistada, o trabalho conjunto com o setor de vacinação teve como objetivo tornar a Unidade um local de referência para os adolescentes da comunidade, através da parceria com uma escola, reforçando os princípios da humanização do atendimento e o de intersetorialidade.

A segunda prática está regulada pelo conceito de aconselhamento, de acordo com a Coordenação Nacional de DSTs e aids, entendido como:

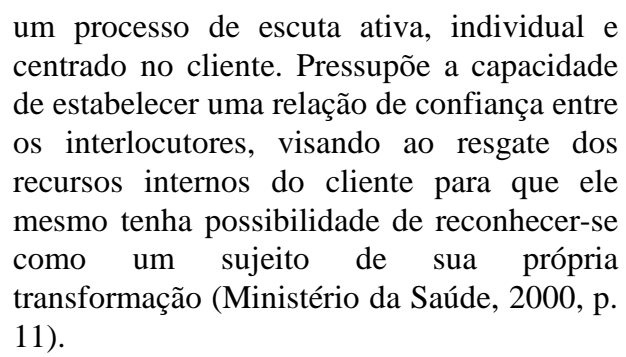

O aconselhamento deve ser regido por três componentes: a) o apoio emocional; b) o apoio educativo e c) a avaliação de riscos (Ministério da Saúde, 2000). Segundo a entrevistada, no aconselhamento individual oferecido há discussão sobre aspectos da vida sexual do usuário, os de risco e os de proteção, o incentivo para incorporação de práticas sexuais seguras e a distribuição de preservativos masculinos e femininos. A partir da descrição das pessoas atendidas, é importante ressaltar que se trata de uma clientela com baixo nível de informação, que tem muitas dúvidas em relação aos sintomas e sinais das DSTs, além do uso correto dos preservativos, ao contrário do que mostram em relação à aids, sobre a qual dizem estar bem informados.

A terceira atividade desenvolvida por Bárbara merecerá um maior detalhamento, por três razões: a) remete-se de modo mais evidente a uma reflexão da necessidade de renovação da atuação psicológica; b) exibe disposição do profissional para superar obstáculos; c) pode ser entendida como original, não estando centrada na doença, mas na saúde. Inicialmente, a interlocutora propôs dois grupos para adolescentes com o objetivo de fomentar o protagonismo juvenil e formar agentes multiplicadores em relação à problemática das DSTs/aids, dentro das instalações da Unidade.

A escolha por trabalhar com o adolescente é apontada em três sentidos: a) sua experiência prévia em elaborar e executar projetos para esta fase do desenvolvimento humano; b) pela maior vulnerabilidade do adolescente em relação às DSTs/aids; c) o cumprimento de uma meta da UBS de vacinar os adolescentes contra Hepatite B' em 2001.

Do seu ponto vista, inicialmente, não houve adesão dos adolescentes às "oficinas" oferecidas, pelos seguintes motivos: a) a ida pouco freqüente deles ao posto de saúde; b) eles acham que sabem tudo e pensam que nada vai lhes acontecer, o que é definido na literatura psicológica especializada como "pensamento mágico"; b) eles têm vergonha ou pouco interesse em participar de "oficinas" que tenham como tema ou apresentem no título: "sexualidade", "autoconhecimento", "crescimento pessoal e social".

Quando questionada sobre este último ponto, a interlocutora conclui que parte do problema ocorria também porque estes termos não pareciam ter muito significado para os adolescentes. Podemos inferir que a diferença de linguagem e de interesse foi um dos marcadores que revelaram dificuldade em organizar seu trabalho em torno da prevenção e da promoção de saúde para esta clientela. Disposta a convocá-los, Bárbara utilizou outra estratégia, descrita a seguir, responsabilizando-se por contribuir com uma meta que a Unidade deveria cumprir, a vacinação contra Hepatite B, aspecto que contempla o princípio da resolutividade, buscando ações condizentes com o perfil epidemiológico.

A estratégia adotada pela entrevistada para superar o que diz ter sido seu primeiro grande desafio foi propor um "curso introdutório de telemarketing" para os adolescentes, conjugado a temáticas cuja discussão era importante, a partir da "reflexão crítica" com esta clientela, além de oferecer os outros serviços que a UBS disponibiliza. Neste sentido, buscou parceria com uma organização não governamental ONG, próxima da UBS, que oferecia atividades artístico-educativas para jovens carentes, considerando a noção de territorialidade. $O$ grupo foi fechado facilmente com 25 adolescentes, sendo realizado nas instalações da ONG, inclusive por falta de espaço físico da Unidade.

A seguir apresentamos uma longa narrativa de reconstrução da tática desenvolvida pela entrevistada, destacando os fragmentos que refletem alguns dos aspectos considerados por Dimenstein (1998) como pontos fundamentais que devem estar presentes no 
trabalho do psicólogo no SUS, particularmente em UBSs:

- Identificar os problemas que requerem atenção prioritária na comunidade. A preocupação em ir paulatinamente percebendo os problemas prioritários aparece desde a sua chegada à Unidade, onde se destaca inclusive a desarticulação entre a unidade e a comunidade. De acordo com Bárbara,

"uma ONG que tem aqui na [UBS] e que fiz uma proposta de saúde, eu sinto que ele [UBS] é desconectado com a comunidade, né? Ele é um posto que não tem vivência na comunidade, essa era uma chance de a gente estar com a comunidade."

Propor ações de saúde em parceria, mediante participação da comunidade, oferecendo procedimentos terapêuticos diversos. Podemos perceber este movimento no fragmento narrativo a seguir:

"E aí a gente fez um trabalho, a gente ia fazer
nessa ONG, né? Nessa parceria... e... aí
tivemos alguns sucessos. No começo do
planejamento, que eu queria fazer igual do
[escola municipal], mas não tinha público, os
adolescentes não se inscreviam, né... só no
sistema de saúde. E então eu tive a idéia de
fazer um curso que chamasse eles e que,
também, é... servisse ao nosso interesse de
saúde aqui. Foi quando eu planejei fazer o
curso telemarketing, que era uma experiência
que eu tinha."

Executar atividades a partir de temas significativos para o mundo do adolescente e do perfil socioeconômico e epidemiológico do público-alvo. Nesta direção, Bárbara organizou seu trabalho como descrito abaixo:

"E então é... o trabalho feito era assim: são oito encontros de uma hora e meia. Os primeiros 45 minutos são apenas relativos a noções de telemarketing, né?. [No segundo momento] a gente tem uma lista e eles escolhem [os temas de interesse]. O que mais apareceu [...] e a gente trabalhou: DSTAIDS, gravidez na adolescência, drogas, uso e abuso de substâncias psicoativas... hum... deixa eu me lembrar, relação de gênero apareceu e... projeto de vid [...]"

Tornar a UBS um local de referência para o adolescente. Ressaltamos que este se tornou um objetivo mais geral do trabalho descrito:
"Então essa fase acabou, essa turma acabou... Aí eles vêm aqui no Posto, tomaram as vacinas de hepatite, principalmente de hepatite, porque o público jovem é o nosso alvo, alguns foram para nutricionista, umas duas meninas que estavam com peso acima... E todos agora participam do trabalho do DST; mês e mês, depois que terminou eles vêm pegar o preservativo."

Esta estratégia distancia-se de um padrão encontrado nas outras trajetórias profissionais descrito como de conflito e/ou de reprodução (Lima, 2005), em dois pontos, em que percebemos um destaque para a força da noção de prevenção e de promoção de saúde desse trabalho, mas que não permite comparações sobre a sua eficácia em relação às atividades oferecidas pelos demais psicólogos: a) não eram encaminhados "adolescentes-problemas", por exemplo, com queixas escolares ou comportamentais, muito comuns nas $\mathrm{UBSs}^{2}$; b) o foco não era resolver um "problema psicológico" restrito ou reforçado pelo contexto socioeconômico desfavorável. Esta tática nos aparece emblemática, porque trata os problemas possíveis de serem encontrados entre os adolescentes tendo como centro difusor a saúde, e não a doença.

Nesta direção, conjuga, por exemplo, o trabalho preventivo de vacinação e do aconselhamento em DSTs/aids, eficiente e caro à saúde coletiva, com a expectativa de refletir sobre o projeto de vida, tendo como local de difusão a UBS, mas sem se limitar a ela. Além disso, percebemos o interesse de identificar precocemente problemas de saúde e fazer o encaminhamento necessário para resolvê-lo.

Tomando esta reconstrução como ponto de partida, percebemos que a atuação psicológica em pauta não tem como foco encontrar ou garantir um

2 Apesar de não podermos estender a discussão desse tema, é preciso ressaltar que o encaminhamento de crianças e adolescentes com "queixa escolar" é um problema prevalente em várias regiões brasileiras, não sendo apenas uma característica de Salvador. A produção do conhecimento sobre o encaminhamento dessa população pelas escolas para o setor da saúde tem apontado a reducionista compreensão do processo de ensino-aprendizagem como atribuição de deficiências individuais, culpabilizando e discriminando negativamente crianças e adolescentes (Patto, 1990; Boarini, 1993; Boarini \& Borges, 1998). Além disso, demonstra o descompasso entre esses setores e revela as fragilidades da formação dos profissionais para lidarem com a problemática do fracasso escolar, exigindo novas abordagens e maior articulação da formação profissional com a realidade educacional brasileira (Boarini, 1996; Meira \& Antunes, 2003). 
emprego para o adolescente, nem tutelá-lo. Parece estar socioeconômica e culturalmente orientada a proporcionar um espaço de reflexão e de troca, que tem como objetivo tornar o adolescente mais atento às dificuldades que encontra no seu dia-a-dia, inclusive em relação aos riscos intrínsecos às experiências cotidianas, de ordem não só sexual, mas sobretudo psicossocial. $\mathrm{Na}$ narrativa abaixo destaca-se o procedimento adotado pela entrevistada para levar a cabo sua atuação:

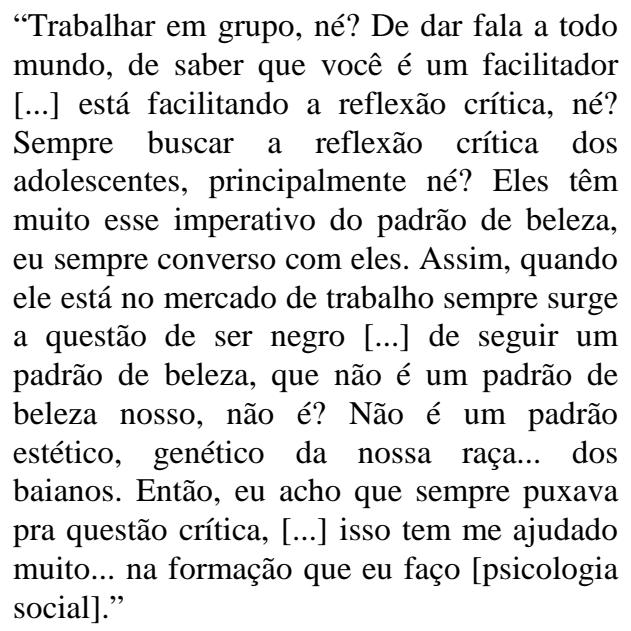

Entendemos, durante a entrevista, que as noções de telemarketing disponibilizadas eram transmitidas com seriedade, já que a interlocutora tinha experiência prévia em treinamento; mas que eram também utilizadas como um pretexto para discutir discriminação étnica e relações de gênero, através de atividades simples e ricas, por exemplo, preparar um currículo com foto. Estas noções eram apresentadas nos primeiros 45 minutos da oficina, e os demais 45 eram reservados às questões pertinentes à prevenção de problemas de saúde. Ao longo dos oito encontros, de acordo com a interlocutora, no processo avaliativo, o "momento da saúde," como os adolescentes assim denominavam, começou a ser esperado com muito entusiasmo, sendo que apenas duas pessoas desistiram. Uma delas desistiu por ter conseguido um trabalho no mesmo horário da realização da oficina e a outra não apresentou justificativa para o desligamento.

\section{CONSIDERAÇÕES FINAIS}

Neste artigo, partimos das críticas decorrentes da inserção dos psicólogos na saúde pública e das orientações para a construção de uma atuação psicológica mais compatível com os objetivos do SUS e balizadas no compromisso social da psicologia. Buscamos discutir com maior propriedade a postura do profissional em seu fazer psicológico frente aos problemas de saúde e psicossociais enfrentados cotidianamente nos serviços públicos de saúde. Neste particular, apresentamos uma estratégia para o trabalho do psicólogo em saúde coletiva: atuação psicológica coletiva (APC). Esta tem como ferramenta principal dois elementos: a) a escuta psicológica cautelosa, ou seja, aposta em uma conduta profissional socioculturalmente orientada; b) reafirmação da importância da subjetividade no processo de saúdedoença-cuidado (Lima, 2005). Nessa perspectiva, a APC deve contemplar esses dois aspectos para a escolha e para a organização das práticas psicológicas oferecidas, sejam estas as de cunho da promoção, preventivo ou de recuperação. Além disso, a APC, ao reafirmar a importância da subjetividade e dos aspectos psicossociais e culturais no processo de saúde-doença-cuidado, aumenta a possibilidade de os psicólogos proporem práticas individuais ou grupais congruentes com os objetivos dos níveis de assistência à saúde.

\section{REFERÊNCIAS}

Almeida-Filho, N., Coelho, M. T. A. \& Peres, M. F. T. (1999). Conceito de Saúde Mental. Revista USP, 43, 100-125.

Bastos, V. \& Achcar, R. (1994). Dinâmica profissional e formação do psicólogo: uma perspectiva de integração. Em Conselho Federal de Psicologia. Psicólogo brasileiro: práticas emergentes e desafios para a formação. (pp. 245-271). São Paulo: Casa do psicólogo.

Bibeau, G. (1992, Julho). Hay uma enfermedad em las americas? Outro camino de la antropologia médica para nuestro tiempo. Trabalho apresentado no VI Congreso de Antropologia em Colombia. Universidad de los Andes: Santa Fé de Bogotá.

Boarini, M. (1993). Unidades Básicas de Saúde: uma extensão da escola pública?. Tese de Doutorado Não-Publicada, Curso de Pós-Graduação em Psicologia. Instituto de Psicologia, Universidade de São Paulo.

Boarini, M. (1996). A formação (necessária) do psicólogo para atuar na saúde pública. Revista Psicologia em Estudo, 1, 93-132.

Boarini, M. \& Borges, R. (1998). Demanda Infantil por serviços de saúde mental: sinal de crise? Estudos em Psicologia (Natal). 3(1), 83-108.

Bock, A. (1999). A Psicologia a caminho do novo século: identidade profissional e compromisso social. Estudos em Psicologia (Natal). 4(2), 315-29.

Bock, A. M. B. (2003). A Psicologia e sua ideologia: 40 anos de compromisso com as elites. Em A. M. B. Bock (org.). Psicologia e o compromisso social. (pp. 15-28). São Paulo: Cortez.

Dimenstein, M. (1998). O psicólogo no contexto do Sistema Único de Saúde (SUS): perfil profissional e perspectivas de 
atuação nas unidades básicas de saúde (UBSs). Tese de Doutorado Não-Publicada, Curso de Pós-Graduação em Ciência da Saúde, Instituto de Psiquiatria, Universidade Federal do Rio de Janeiro.

Geertz, C. (1989). A interpretação das culturas. Rio de Janeiro: LTC.

Goldberg, J. (2001). Reabilitação como processo: o centro de atenção psicossocial. Em A. Pitta (Org.), Reabilitação Psicossocial no Brasil. (pp. 33-47). São Paulo: HUCITEC.

Lima, M. (2005). Atuação Psicológica em Serviços de Saúde de Salvador: do ponto de vista dos psicólogos. Tese de Doutorado Não-Publicada, Curso de Pós-Graduação em Saúde Coletiva, Instituto de Saúde Coletiva, Universidade Federal da Bahia.

Lo Bianco, A. C., Bastos, A. V., Nunes, M. L. \& Silva, R. C. (1994). Concepções e atividades emergentes na psicologia clínica: implicações para a formação. Em Conselho Federal de Psicologia. Psicólogo brasileiro: Práticas emergentes e desafios para a formação. (pp. 7-79). São Paulo: Casa do psicólogo.

Meira, M. \& Antunes, M. (Org.) (2003). Psicologia Escolar: teorias e críticas. São Paulo: Casa do Psicólogo.

Ministério da Saúde (2000). Aconselhamento em DST, HIV e AIDS: diretrizes e procedimentos básicos. Brasília.
Moskovics, J. (2000). O aconselhamento e testagem anônima em HIV com estratégia preventiva. Em J. Sarriera (Org.), Psicologia Comunitária: estudos atuais. (pp. 121-147). Porto Alegre: Sulina.

Paim, J. (1999). A reforma sanitária e os modelos assistenciais. Em M. Rouquayrol \& N. Almeida-Filho. Epidemiologia $e$ Saúde. (pp. 473-487) Rio de Janeiro: MEDSI.

Patto, M. (1990, $2^{\text {a }}$ ed.). A produção do Fracasso Escolar: histórias de submissão e rebeldia. São Paulo: Casa do Psicólogo.

Ricoeur, P. (1991). From text to action: essays in hermeneutics, II. Evanston, Illinois: Northwestern University Press.

Russo, J. (2002). O mundo psi no Brasil. Rio de Janeiro: Zahar. Silva, R. (1992). A formação em psicologia para o trabalho na saúde pública. Em F. Campos (Org.), Psicologia e Saúde: repensando práticas. (pp. 25-40). São Paulo: Hucitec.

Spink, M. (2003). Psicologia Social e saúde: práticas, saberes e sentidos. Petrópolis: Vozes.

Recebido em 11/07/2005 Aceito em 30/09/2005 